\title{
Estimator Parameter Tegangan Jaringan Tiga Fasa Berbasis D-SOGI PLL
}

\author{
Iwan Setiawan ${ }^{1 *}$, Mochammad Facta $^{2}$, Ardyono Priyadi $^{3}$, Mauridhi Hery Purnomo ${ }^{4}$
}

\begin{abstract}
Phase locked loop (PLL) is a feedback system which plays an important role in on-grid power converters. The main function of the PLL is to get a variety of grid voltage information, such as phase and magnitude. This information are used as the basis for the synchronization process between power equipment with the grid. The main purpose of this paper is to model as well as to compare the performance of one type of PLL that well known as Dual-Second Order Generalized Integrator Phase-Locked Loop with the Synchrounous Reference Frame SRF-PLL that could be regard as a standard PLL. Based on simulation results, the performance of D-SOGI PLL in steady state is more superior than SRF-PLL, mainly in unbalanced voltage conditions.
\end{abstract}

Intisari-Phase locked loop (PLL) adalah sebuah sistem umpan balik yang memegang peran penting dalam sistem-sistem konverter terkoneksi jaringan listrik. Fungsi utama PLL adalah mendapatkan beragam informasi parameter jaringan yaitu seperti phase dan magnitude tegangan. Informasi-informasi tersebut selanjutnya digunakan sebagai dasar proses sinkronisasi peralatan dengan jaringan listrik. Tujuan utama paper ini adalah memodelkan sekaligus membandingkan unjuk kerja salah satu jenis PLL yang dikenal dengan nama Dual Second Order Generalized Integrator Phase-Locked Loop dengan SRF-PLL yaitu sebuah PLL yang relatif standar. Berdasarkan hasil simulasi, unjuk kerja D-SOGI PLL dalam keadaan tunaknya lebih unggul dibandingkan SRFPLL terutama untuk kondisi jaringan listrik tiga phase tidak seimbang.

Kata Kunci- Phase locked loop, singkronisasi, Dual Second Order Generalized Integrator PLL, SRF-PLL.

\section{PENDAHULUAN}

Konverter terkoneksi jaringan (On Grid Converter) merupakan salah satu komponen penting dalam bidang pembangkitan energi listrik terbarukan yang terhubung langsung dengan jaringan listrik.

Selain dimanfaatkan sebagai jembatan penghubung antara sumber daya terbarukan dan jaringan listrik, sistem On Grid Converter [1][2] dewasa ini juga dapat ditemukan dalam sejumlah perangkat sistem lainnya yaitu seperti sistem

${ }^{1,2}$ Dosen Departemen Teknik Elektro Universitas Diponegoro (Undip) Semarang, Jalan Prof. H. Soedarto SH, Kampus

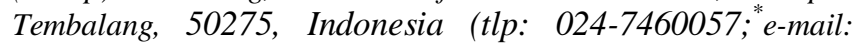
iwansetiawan@live.undip.ac.id)

${ }^{3,4}$ Dosen Jurusan Teknik Elektro Institut Teknologi Sepuluh Nopember (ITS) Surabaya, Jalan Arif Rahman Hakim, Surabaya, 60111, Indonesia (tlp: 031 -5994251)

penyearah aktif AC/DC [3][4], filter daya aktif (APF), dan sistem transmisi high-voltage direct current - HVDC [5][6].
Berdasarkan kebutuhan interkoneksi jaringan (Grid connection requirements), sistem On Grid Converter harus tetap dapat beroperasi dan terkoneksi dengan jaringan listrik walaupun jaringan tersebut sedang mengalami gangguan yang disebabkan beberapa kondisi, yaitu seperti kerusakan perangkat jaringan, koneksi dan interkoneksi beban listrik yang relatif besar, serta ketidakseimbangan tegangan antar phase.

Untuk mencapai tujuan tersebut, sistem On Grid Converter secara teknis harus memiliki kemampuan mendeteksi gangguan secara cepat sehingga informasi-informasi besaran jaringan listrik yang dibutuhkan oleh sistem kontrol konverter yaitu seperti informasi sudut phase dan magnitude komponen tegangan urutan positif dan urutan negatif tetap tersedia secara akurat.

komponen yang bertanggung jawab menyediakan beragam informasi pada sistem On Grid Converter tersebut dikenal dengan nama Phase locked Loop (PLL). Secara teknis PLL pada dasarnya adalah sebuah sistem kontrol umpan balik phase.

Tujuan utama paper ini adalah memodelkan dan sekaligus membandingkan salah satu jenis PLL yang dikenal dengan nama Dual Second Order Generalized Integrator PhaseLocked Loop (D-SOGI PLL) [7-9] dengan sebuah PLL yang relatif standar: Synchrounous Reference Frame SRF-PLL. Perangkat lunak yang digunakan dalam penelitian ini adalah Matlab/Simulink.

\section{MODEL SRF PLL}

Salah satu jenis PLL standar yang umum digunakan untuk mendeteksi sudut phase, magnitude tegangan dan frekuensi adalah SRF PLL seperti ditunjukan pada gambar (1). Berdasarkan gambar tersebut, nampak bahwa terdapat tiga blok komputasi utama dalam sistem SRF-PLL: (1) Blok transformasi Clark, (2) blok transformasi Park dan (3) Blok sistem kontrol umpan balik Proportional Integral (PI).

Dalam sistem SRF-PLL, transformasi Clark dan Park berfungsi untuk mengubah representasi variabel tiga phase: $v_{a}, v_{b}$, dan $v_{c}$ menjadi dua buah variabel ortogonal $v_{d}$ dan $v_{a}$ dalam sebuah bingkai referensi yang berotasi dalam arah putaran positif (berlawanan arah jarum jam). Persamaan (2.1) dan (2.2) berikut berturut-turut memperlihatkan model matematis transformasi Clark dan Park.

$$
\begin{aligned}
& {\left[\begin{array}{l}
\mathrm{v}_{\alpha} \\
\mathrm{v}_{\beta}
\end{array}\right]=\frac{2}{3}\left[\begin{array}{ccc}
1 & -\frac{1}{2} & -\frac{1}{2} \\
0 & \frac{\sqrt{3}}{2} & -\frac{\sqrt{3}}{2}
\end{array}\right]\left[\begin{array}{l}
\mathrm{v}_{\mathrm{a}} \\
\mathrm{v}_{\mathrm{b}} \\
\mathrm{v}_{\mathrm{c}}
\end{array}\right]} \\
& {\left[\begin{array}{l}
\mathrm{v}_{\mathrm{d}} \\
\mathrm{v}_{\mathrm{q}}
\end{array}\right]=\left[\begin{array}{cc}
\cos \theta & \sin \theta \\
-\sin \theta & \cos \theta
\end{array}\right]\left[\begin{array}{l}
\mathrm{v}_{\alpha} \\
\mathrm{v}_{\beta}
\end{array}\right]}
\end{aligned}
$$




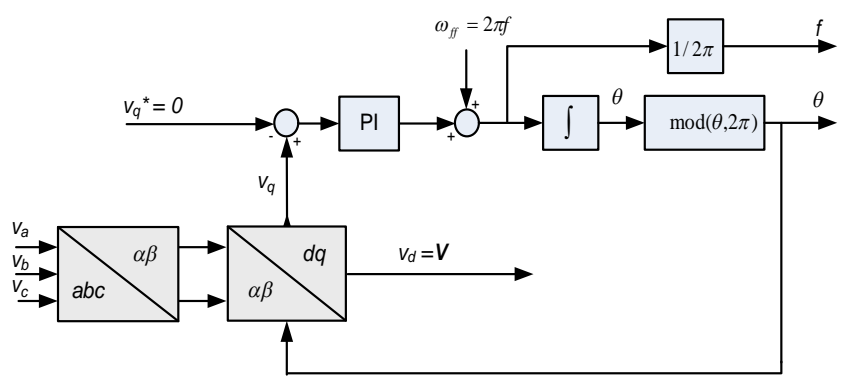

Gambar 1: Diagram Blok SRF-PLL

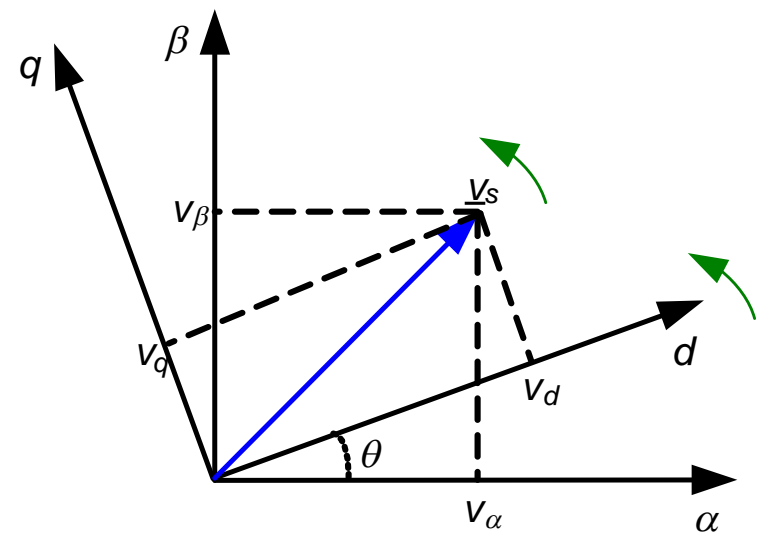

Gambar 2: Sinkronisasi tegangan jaringan listrik 3 phase

Pada sistem SRF-PLL, sistem kontrol umpan balik PI secara fungsional digunakan untuk meregulasi komponen quadrature dari vektor tegangan jaringan listrik $\left(v_{q}\right)$ pada nilai referensi nol sedemikian sehingga setiap saat akan terjadi sinkronisasi antara bingkai referensi $d q$ dengan vektor tegangan $\alpha-\beta$ yang berotasi seperti diperlihatkan pada gambar (2).

Berdasarkan topologinya, SRF-PLL akan bekerja optimal dalam mendeteksi sudut phase dan magnitude komponen vektor tegangan urutan positif pada jaringan listrik seimbang. Unjuk kerja SRF-PLL akan menurun drastis jika tegangan listrik tiga phase yang dideteksi memiliki ketidakseimbangan antar phase. Hal ini disebabkan pada jaringan listrik tidak seimbang, selain komponen vektor tegangan urutan positif (vektor tegangan yang berotasi berlawanan arah jarum jam), juga akan muncul komponen vektor tegangan urutan negatif (vektor tegangan yang berotasi searah jarum arah jarum jam). Untuk kasus jaringan tidak seimbang, informasi magnitude tegangan, frekuensi dan phase yang dideteksi oleh SRF-PLL ini relative tidak akurat.

\section{MODEL D-SOGI PLL DAN PERANCANGAN}

D-SOGI-PLL pada dasarnya adalah jenis PLL hasil pengembangan dari SRF-PLL. Berbeda dengan SRF-PLL yang hanya mampu mendeteksi komponen tegangan jaringan urutan positif, dalam sistem DSOGI-PLL, kedua komponen vektor tegangan, baik urutan positif maupun urutan negatif dapat dideteksi secara simultan, sehingga dengan demikian Iwan Setiawan: Estimator Parameter Tegangan Jaringan ...
PLL jenis ini sangat tepat digunakan sebagai komponen sinkronisasi pada sistem jaringan tidak seimbang.

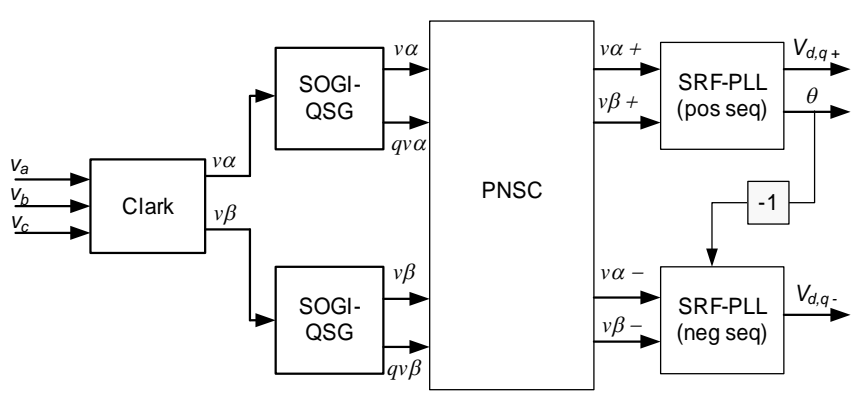

Gambar 3: Diagram blok DSOGI-PLL

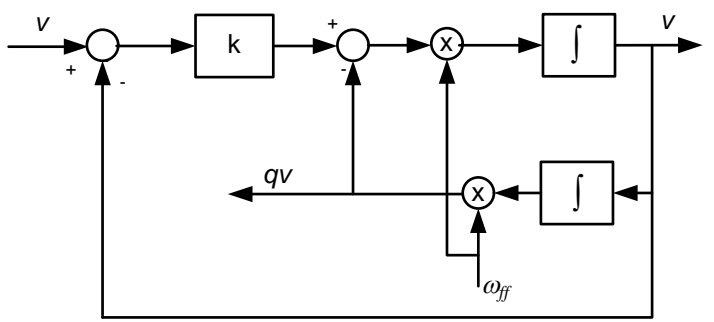

Gambar 4: Diagram Blok SOGI-QSG

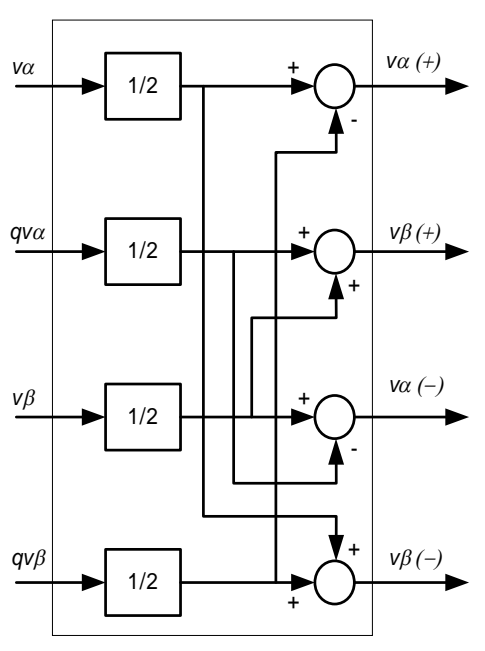

Gambar 5. Diagram blok PNSC

Gambar (3) memperlihatkan diagram blok D-SOGI-PLL. Seperti nampak pada gambar tersebut, DSOGI-PLL ini tersusun dari empat blok fungsional utama: Transformasi Clark, (2) Second Order Generalized Integrator Quadrature Signal Generator (SOGI-QSG), (3) PositiveNegative Signal Calculator (PNSC) dan (4) dua buah Synchronous Reference Frame-Phase Locked Loop (SRF-PLL) yang masing-masing digunakan untuk mendeteksi komponen urutan positif dan negatif dari vektor tegangan.

p-ISSN:1693 - 2951; e-ISSN: 2503-2372 
Dalam sistem DSOGI-PLL, dua buah pembangkit sinyal berbasis integrator orde 2 seperti nampak pada gambar (4) digunakan untuk membangkitkan sinyal kuadratur $v_{\alpha}$ dan $v_{\beta}$, Dalam rangkaian ini, $\omega_{f f}$ adalah frekuensi nominal jaringan yang digunakan sebagai bias.

Berdasarkan sinyal $v_{\alpha}$ dan $v_{\beta}$ beserta sinyal-sinyal orthogonalnya, selanjutnya dapat dihitung vektor tegangan yang berotasi berlawanan arah jarum jam dan vektor tegangan searah jarum jam dengan menggunakan blok PNSC seperti nampak pada gambar (5). Transformasi besaran vektor yang berotasi ini selanjutnya diekstraksi menjadi komponen tegangan urutan positif dan negatif oleh blok SRF-PLL.

\section{SimUlasi DAN PEMBAHASAN}

Dalam paper ini penyelidikan unjuk kerja PLL dilakukan lewat studi simulasi. Perangkat lunak pemodelan yang digunakan dalam penelitian ini adalah Matlab/Simulink. Penyelidikan unjuk kerja meliputi tanggapan PLL terhadap perubahan tegangan tiga phase, baik tegangan seimbang maupun perubahan tegangan tiga phase tidak seimbang.

\section{A. Simulasi SRF-PLL}

Gambar (6) memperlihatkan profil tegangan tiga phase dengan frekuensi $50 \mathrm{~Hz}$ yang akan dideteksi oleh SRF-PLL. Berdasarkan gambar tersebut nampak bahwa dari detik ke-0 sampai ke-0.125 magnitude tegangan jaringan listrik bersifat seimbang dan bernilai 310 volt, sedangkan dari detik ke-0.125 sampai detik ke-0.325 nilai magnitude ketiga fasa mengalami penurunan menjadi 200 volt, sedangkan mulai detik ke 0.325 , magnitude tegangan mengalami perubahan asimetris dimana magnitude phasa A bernilai 200 sedangkan fasa B dan C masing-masing bernilai 310 volt. Hasil estimasi magnitude tegangan, frekuensi dan phase oleh SRF-PLL ini berturut-turut diperlihatkan pada gambar (7) sampai gambar (9). Dalam studi simulasi yang dilakukan, besaran penguat Proporsional dan Integral ditetapkan berturut-turut sebesar 10 dan 20.

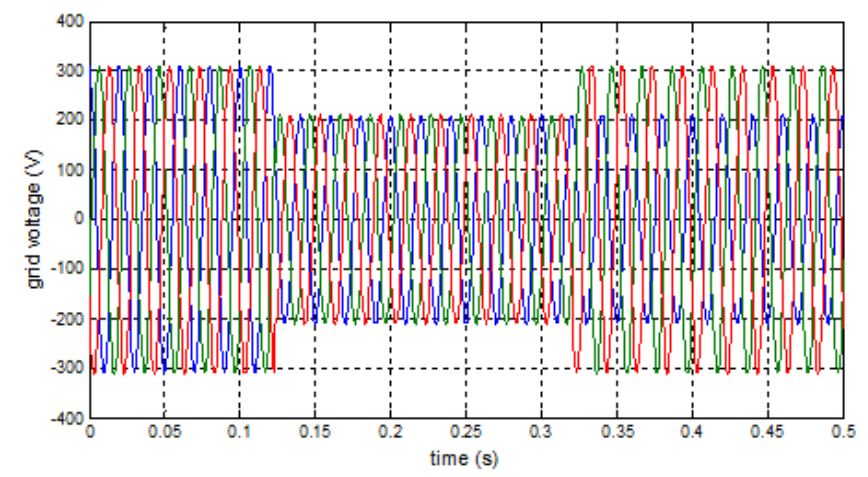

Gambar 6: Profil tegangan jaringan listrik 3 phase input SRF-PLL

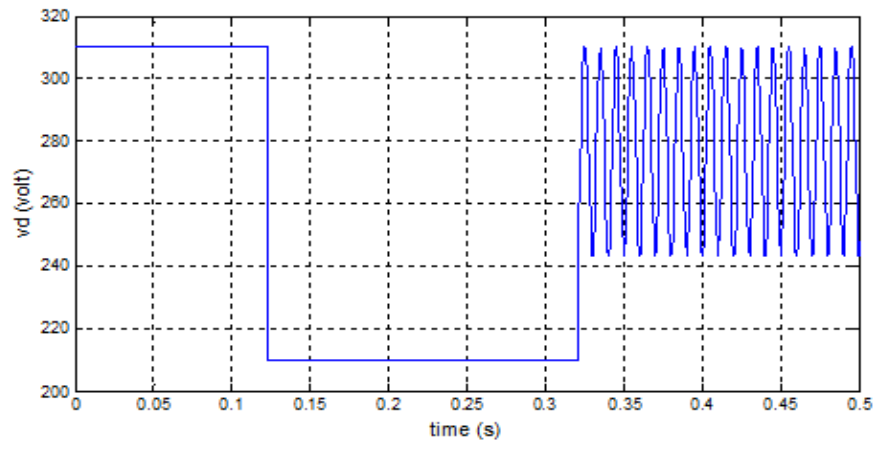

Gambar 7: Hasil deteksi magnitude tegangan dengan SRF-PLL untuk profil tegangan pada gambar 6

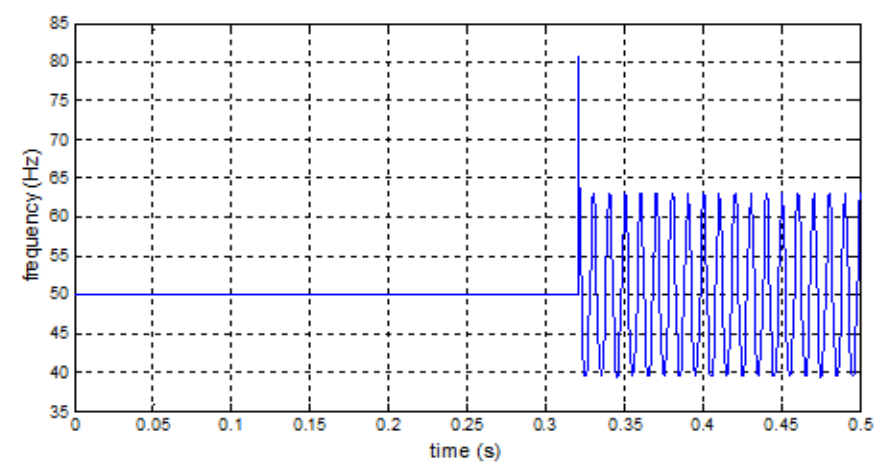

Gambar 8: Hasil deteksi frekuensi dengan SRF-PLL untuk profil tegangan pada gambar 6

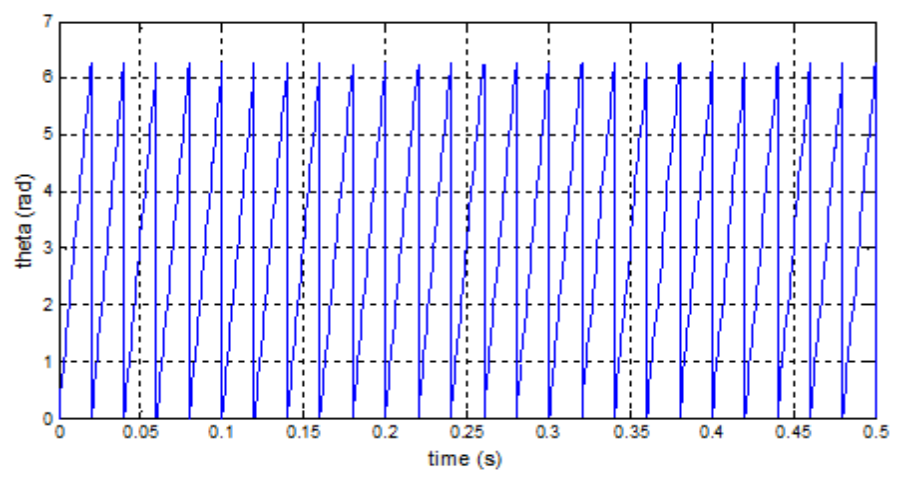

Gambar 9: Hasil deteksi sudut phase dengan SRF-PLL untuk untuk profil tegangan pada gambar 6

Seperti nampak dari hasil simulasi, keluaran magnitude tegangan, frekuensi dan sudut phase hasil deteksi SRF-PLL untuk tegangan listrik seimbang relatif (detik ke-0 sampai detik ke 0.325) menghasilkan nilai relatif akurat, sedangkan untuk kondisi tegangan listrik tidak seimbang (mulai detik ke0.325 ) hasil pendeteksian menunjukan fluktuasi sebesar dua kali frekuensi jaringan listrik.

\section{B. Simulasi DSOGI-PLL}

Untuk profil tegangan gambar (6), hasil estimasi magnitude komponen vektor tegangan urutan positif, komponen vektor tegangan urutan negatif, frekuensi dan sudut phase oleh DSOGI-PLL berturut-turut diperlihatkan pada gambar (10) sampai gambar (13). 


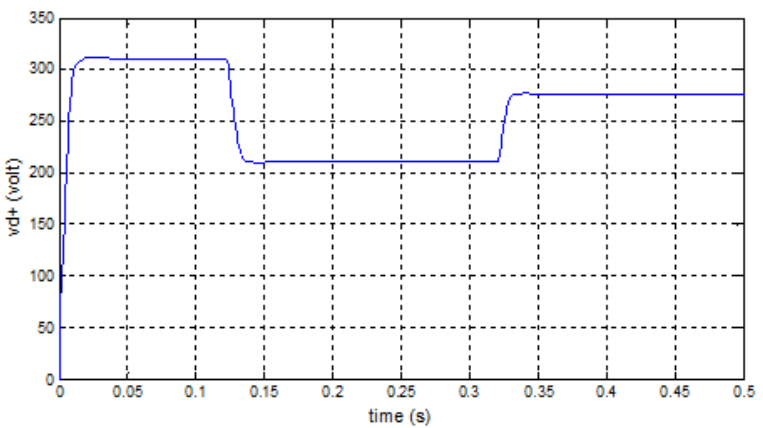

Gambar 10: Hasil deteksi vd+ dengan DSOGI-PLL untuk profil tegangan gambar 6

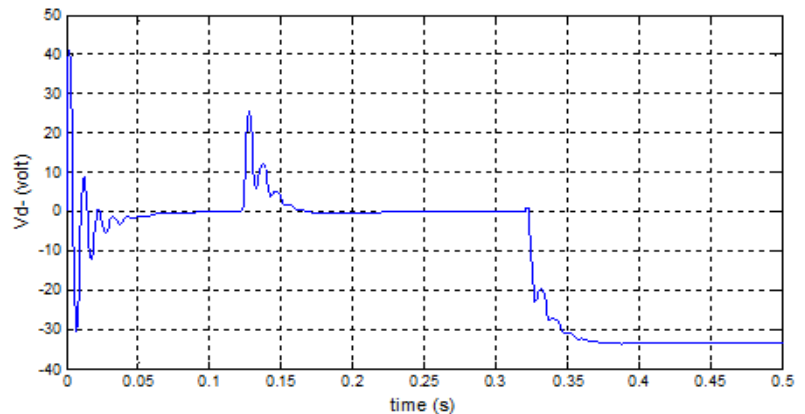

Gambar 11: Hasil deteksi vd- dengan DSOGI-PLL untuk profil tegangan gambar 6

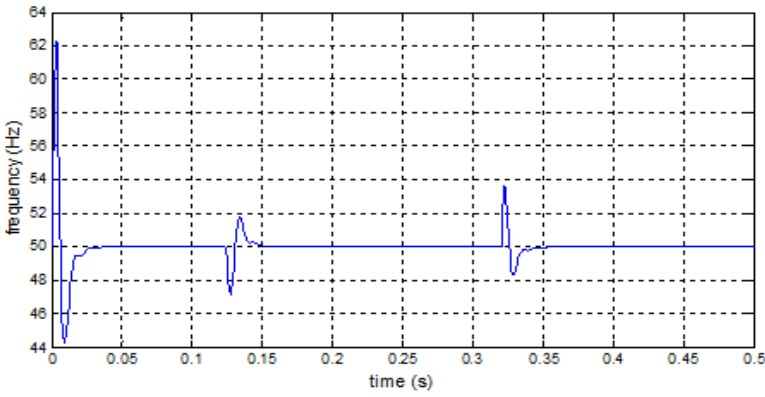

Gambar 12: Hasil deteksi frekuensi dengan DSOGI-PLL untuk profil tegangan gambar 6

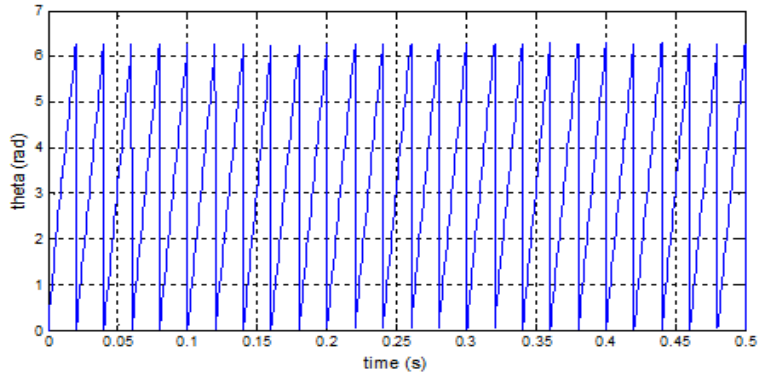

Gambar 13: Hasil deteksi phase dengan DSOGI-PLL untuk profil tegangan gambar 6

Seperti nampak dari hasil-hasil simulasi tersebut dan dengan membandingkan dengan profil tegangan jaringan pada gambar 6, keluaran deteksi komponen vektor tegangan, baik urutan positif maupun negatif, frekuensi serta phase yang

Iwan Setiawan: Estimator Parameter Tegangan Jaringan ... diperoleh oleh DSOGI-PLL dalam keadaan steady-nya relative akurat, baik untuk tegangan jaringan listrik tiga phase seimbang maupun tegangan jaringan tidak seimbang. Tetapi walaupun demikian ditinjau dari untuk kerja transiennya, keluaran D-SOGI PLL dalam menanggapi perubahan tegangan menunjukan respon yang relatif lebih lambat dibandingkan sistem SRF-PLL

\section{KESIMPULAN}

Berdasarkan studi simulasi yang telah dilakukan nampak bahwa DSOGI-PLL secara umum mampu mengestimasi besaran listrik tiga phase secara akurat baik untuk kondisi tegangan tiga phase seimbang maupun untuk kondisi tegangan tidak seimbang, sedangkan SRF-PLL hanya mampu mengestimasi secara akurat besaran listrik untuk kondisi seimbang saja.

Topik selanjutnya dari penelitian ini adalah realisasi DSOGI-PLL kedalam bentuk algoritma real-time yang akan diimplementasikan dalam sistem Digital Signal Controller (DSC)

\section{UCAPAN TERIMA KASIH}

Penulis mengucapkan terimakasih kepada Universitas Diponegoro, Undip Semarang atas dukungan dana untuk penelitian ini yaitu dalam skema Hibah penelitian RPP

\section{REFERENSI}

[1] [1] GAMBUT, v., HARTATI, R., WEKING, A.. ANALISIS ENERGI LISTRIK TERSELAMATKAN PADA PENYULANG BANGLI PT. PLN (PERSERO) AREA BALI TIMUR DENGAN BEROPERASINYA PLTS KAYUBIHI. Majalah Ilmiah Teknologi Elektro, vol 15, no 1 (2016)

[2] SUGIRIANTA, I., GIRIANTARI, I., KUMARA, I.. Analisa Keekonomian Tarif Penjualan Listrik Pembangkit Listrik Tenaga Surya 1 MWp Bangli Dengan Metode Life Cycle Cost. Majalah Ilmiah Teknologi Elektro, vol 15, no.2 ( 2016)

[3] Zarif, M., and M. Monfared. "Step-by-step design and tuning of VOC control loops for grid connected rectifiers." International Journal of Electrical Power \& Energy Systems 64 (2015): 708-713.

[4] Bouafia, Abdelouahab, Jean-Paul Gaubert, and Fateh Krim. "Design and implementation of predictive current control of three-phase PWM rectifier using space-vector modulation (SVM)." Energy Conversion and Management 51.12 (2010): 2473-2481.

[5] Messina, A. R., M. A. Perez, and E. Hernandez. "Co-ordinated application of FACTS devices to enhance steady-state voltage stability." International journal of electrical power \& energy systems 25.4 (2003): 259-267.

[6] J. W. Kolar and T. Friedli, "The essence of three-phase PFC rectifie systems," in Proc. IEEE Int. Telecom. Energy Conf., 2011, pp. 1-27.

[7] Rodriguez, P., Bergas, J., Gallardo, J.A. A new positive sequence Voltage Detector for Unbalanced Power System. EPE-PEMC 2002 Dubrovnik and Cavat.

[8] P. Rodriguez, R. Teodorescu, I. Candela, A.V. Timbus, M. Liserre, and F. Blaabjerg, New Positive-sequence Voltage Detector for Grid Synchronization of Power Converters under Faulty Grid Conditions. Power Electronics Specialists Conference, 2006. PESC '06. 37th IEEE. Power Electronics Specialists Conference. PESC '06.37th IEEE, 1-7. 18-6-2006

Rodriguez, P., Pou, J., Bergas, J., Candela, J., Burgos, R. and Boroyevich, D. Decoupled double synchronous reference frame PLL for power converters control. IEEE Transactions on Power Electronics, vol. 22, no. 2, pp. 584-592, 2007.

p-ISSN:1693 - 2951; e-ISSN: 2503-2372 